\title{
FUSÕES E AQUISIÇÕES NO BRASIL: REFLEXÕES ACERCA DA EVOLUÇÃO DO VOLỦME DE TRANSAÇÕES
}

MERGER AND AQUISITIONS: REFLECTIONS OVER THE EVOLUTION OF THE VOLUME OF TRANSACTIONS

\section{Talieh Shaikhzadeh Vahdat Ferreira}

taliehv@gmail.com

Universidade Federal da Paraíba, João Pessoa/PB, BRASIL

\author{
Aldo Leonardo Cunha Callado \\ aldocallado@yahoo.com.br \\ Universidade Federal da Paraíba, João Pessoa/PB, BRASIL
}

\begin{abstract}
Resumo
Este estudo buscou analisar o desenvolvimento do volume de Fusões e Aquisições (F\&A) no Brasil e sua relação com fatores macroeconômicos que possivelmente explicam seu comportamento. Nesse sentido, realizou-se uma revisão de literatura relacionada a temática e análises de dados secundários disponibilizados pela KPMG referentes ao período de 2002 a 2014. As reflexões exploraram os fatores influenciadores desempenhados pelo governo brasileiro e o mercado externo considerando-se duas perspectivas: a origem do capital e setor de atuação das empresas envolvidas. Os dados sugerem que o mercado brasileiro apresentou um amadurecimento, visto que se observou uma tendência de crescimento de forma sustentável no período, mesmo com diferentes forças macroeconômicas internas e externas atuando. Destaca-se como contribuições deste estudo, a ampliação da compreensão das mudanças econômicas que expliquem a evolução das F\&A no Brasil em um período que abrange significativas turbulências e instabilidades econômicas mundialmente.
\end{abstract}

Palavras-chave: Fusões e Aquisições. Brasil. Fatores Macroeconômicos.

\begin{abstract}
This study analyze the development of Merger and Acquisitions (M\&A) volume in Brazil and its relation with macroeconomic factors that can possible explain its behavior. In these direction, it was performed a literature review and analysis based on secondary data from 2002 to 2014 provided by KPMG. The reflections explore the contributing factors implemented by the Brazilian government and the external market taking into account two perspectives: the origin of the capital and company's activity sector. The data suggests that the Brazilian market had a ripening due to an observable sustainable growth trend in the period even with the impacts of different internal and external macroeconomic forces. It stands out as contributions of this study the comprehension expansion of the economic changes that explain the M\&A evolution in Brazil in a period with significant turbulences and economic instability worldwide.
\end{abstract}

Keywords: Merger and Acquisitions. Brazil. Macroeconomic Factors. 


\section{Introdução}

As operações de combinações de negócios entre diferentes empresas, principalmente as Fusões e Aquisições (F\&As), são eventos que envolvem organizações e que ainda permanecem controversos na literatura. Muitos são os questionamentos acerca dos possíveis benefícios gerados a partir dessas transações para o desempenho econômico-financeiro das companhias adquirentes ou resultantes dessas integrações. As combinações de negócios, mais especificamente as F\&A, representam eventos corporativos complexos, dinâmicos e que são realizados envolvendo empresas, tornando-se objeto de estudo de várias ciências sociais que ainda buscam respostas para o efeito dessas transações na situação econômico-financeira de uma companhia.

Nas duas últimas décadas ocorreram mudanças estruturais significativas na economia brasileira que geraram uma redução do papel do Estado na economia, tornando-a mais atrativa aos investidores e tendo como consequência uma ampliação no volume de F\&A (AMANN; BAER, 2008). Dentre as alterações que tem criado um ambiente propício para a expansão e desenvolvimento da atividade empresarial e crescentes volumes de Investimento Estrangeiro Direto (IED), destacam-se os movimentos de privatização, estabilização da economia com o Plano Real e a atuação do Banco Nacional de Desenvolvimento Econômico e Social (BNDES) como fomentador dos processos de F\&A (CANO, 2002; BRITTO, 2002).

Entre os anos 2002 e 2014, este ambiente passou por períodos de turbulência e instabilidade gerados por diversos fatores, tais como as expressivas variações do Produto Interno Brasileiro (PIB) brasileiro e a crise econômica mundial iniciada em 2008. Por sua vez, estas variações tem o potencial de alterar a disposição dos investidores em realizar novos investimentos e a atratividade do país para estas operações, justificando a busca da compreensão de seu impacto nos movimentos de F\&A.

De acordo com Wood Jr. et al. (2004), no Brasil, o crescimento do número de fusões e aquisições acompanhou o processo de liberação econômica, sendo favorecida a partir de três diferentes perspectivas: (i) a desregulamentação dos mercados locais, associada às tendências internacionais em direção à globalização, que permitiu que empresas estrangeiras adquirissem empresas brasileiras; (ii) programas de privatização que possibilitaram que o capital privado, nacional ou internacional, investissem em setores anteriormente controlados pelo governo, e (iii) a elevada competição internacional, associada à acelerada mudança tecnológica, que gerou uma maior busca das companhias por eficiência e qualidade para sobreviverem vendo nas transações de F\&A uma saída rápida para acompanhar estas alterações.

Antoniou et al. (2006) consideram que em um nível macroeconômico, as F\&A representam uma realocação massiva de ativos dentro ou através de diferentes indústrias, o que frequentemente acaba permitindo com que essas firmas dobrem de tamanho em pouco tempo. Os mesmos autores apresentam também que essas operações tendem a ocorrer em ondas e em grupos de indústrias; e isso é facilmente entendido como uma transação que pode mudar radicalmente a estrutura competitiva das indústrias afetadas.

Adicionalmente, considerando-se a crescente relevância do Brasil para a economia mundial e a atratividade de seu mercado para os movimentos de F\&A em meio às significativas alterações econômicas no período, este artigo visa ampliar a compreensão dos efeitos das principais mudanças econômicas no período que busquem explicar a evolução das transações de F\&A no Brasil.

Para a sua elaboração utilizou-se periódicos, artigos e relatórios nacionais e internacionais que buscam explicar os principais fatores que influenciaram as F\&As no Brasil no período entre 2002 e 2014 . Os dados secundários foram obtidos nos relatórios da Klynveld Peat Marwick Goerdeler (KPMG)-Corporate, pois apresentam um maior nível de detalhamento possibilitando uma análise mais detalhada dos fatores que influenciaram os movimentos de F\&A (CAMARGO; BARBOSA, 2005). As análises foram elaboradas sob duas perspectivas: a origem do capital envolvido nas operações, ou seja, se são transações puramente nacionais ou se envolvem saída ou entrada de capital; e a representatividade por setor.

O artigo está organizado em quatro seções. Além dessa introdução, a seção seguinte traz uma revisão dos principais conceitos de F\&A e análises descritivas das mudanças macro econômicas, assim como a evolução das F\&A no período investigado. Na seção subsequente, buscou-se analisar as relações entre o desenvolvimento das F\&A e os eventos macroeconômicos e setoriais que poderiam explicar seu comportamento. Por fim, na última seção, são apresentadas as considerações finais da pesquisa. 


\section{Revisão de literatura}

\section{Fusão e Aquisição}

Uma combinação de entidades é resultado de duas ações, a saber: processo de aquisição em absoluto (compra de interesses); ou processo de união (comunhão) de interesses de propriedade (LOPES, 2003). De acordo com a Lei Federal no 6404/76, Art. 228, as fusões podem ser definidas como uma "operação pela qual se unem duas ou mais sociedades para formar sociedade nova, que lhes sucederá em todos os direitos e obrigações". $\mathrm{Na}$ fusão ou consolidação, as companhias envolvidas na operação geralmente possuem porte e ramo de atividades semelhantes e combinam-se por meio de uma simples permuta de ações, dando origem a outra firma (ROSS et al., 2002).

As aquisições são definidas pelo Art. 227 como uma “operação pela qual uma ou mais sociedades são absorvidas por outra, que lhes sucede em todos os direitos e obrigações". Portanto, uma aquisição ocorre quando uma firma compra, de forma total ou parcial, as ações circulantes ou ativos de outra firma (DODD, 1980). As aquisições podem ser conduzidas de forma hostil ou amigável, podendo-se desenvolver de duas formas: (i) assumindo-se o controle de todos os passivos pela compra da maioria das ações da empresaalvo; (ii) pela compra dos ativos líquidos da firmaalvo, podendo assim selecionar os ativos desejáveis e excluir os passivos de alto risco (STRAUB, 2007).

Estas uniões normalmente se apresentam como uma alternativa de expansão ou desenvolvimento que, a princípio, oferece vantagens para todas as partes envolvidas na transação (EL HAJJ, 1999). Podem-se destacar três pontos que fundamentalmente diferenciam as fusões de aquisições: a) personalidade jurídica: em uma fusão ocorre a criação de uma nova firma que é a junção das anteriores, já em aquisições uma das companhias mantém sua identidade jurídica; b) forma de pagamento: em fusões ocorre uma permuta de ações enquanto que em aquisições a forma de pagamento pode variar entre dinheiro, ações e títulos; e c) atividade: em fusões geralmente as companhias possuem a mesma atividade fim, nas aquisições é comum operações que envolvem companhias atuando em setores distintos (CAMARGOS; BARBOSA, 2003).

De acordo com Tanure e Cançado (2005), mesmo que teoricamente as transações de fusões e aquisições apresentem características que as diferenciem, em termos práticos, a quantidade de fusões reais é tão reduzida que se podem englobar os dois tipos de transações basicamente em aquisições. Mesmo que as transações de fusões ocorram por meio da combinação de empresas que deixam de existir e formam uma terceira, com nova identidade, sem predominância das empresas anteriores, na realidade, o que acontece é que a empresa constituída passa a ser controlada por uma das extintas, aproximando-se das transações de aquisições (TANURE; CANÇADO, 2005).

Segundo Triches (1996), a fusão ou a consolidação caracteriza-se pela forma ou pelo método que conjunto de empresas escolhe para a organização de uma nova entidade, muitas vezes com nova denominação e administração constituída segundo a proporção dos bens patrimoniais reunidos ou fundidos, com o objetivo de multiplicar sua capacidade de produção, de comercialização e de influência sobre o mercado. Já a aquisição ocorre quando uma empresa ou um grupo de investidores adquire, total ou parcialmente, o patrimônio ou o controle acionário de outra empresa.

\section{Aspectos Influenciadores das F\&A}

Há uma diversidade de fatores que influenciam a tomada de decisão para a realização das F\&A. De acordo com o objetivo deste movimento, o processo de realização do mesmo pode ser classificado como: horizontal, vertical e conglomerado ou coseguro (ROSS et al., 2002). Os processos horizontais caracterizam-se pela união de companhias que atuam no mesmo ramo de atividade, normalmente sendo concorrentes. As razões que geralmente explicam este tipo de transação são os resultados obtidos com a operação (economias de escala e redução de custos). Os processos verticais ocorrem quando empresas de uma mesma cadeia produtiva se unem. Este tipo de integração permite diminuir custos de transação externos devido a imperfeições do mercado, com a possibilidade de gerar economias de escala e sinergias. Por fim, a formação de conglomerado ou co-seguro caracterizam-se pela união de duas empresas de ramos de atividades distintas e não relacionadas resultando em uma diversificação de investimentos, o que pode reduzir riscos e gerar novas oportunidades de investimento (SUEN; KIMURA, 1997). Assim, os processos de F\&A refletem a estratégia de crescimento e desenvolvimento das empresas envolvidas.

Há uma diversidade de estudos que buscam explicar as motivações pelas quais uma empresa buscaria 
realizar uma fusão ou aquisição. Uma vertente de estudos entende que estes processos têm motivações eminentemente microeconômicas, a saber: um modo de entrada em novos mercados ou países (BHAGAT, 2011); diversificação de produtos e integração da cadeia produtiva (SPOHR; SILVEIRA, 2012); busca de poder de monopólio (CAMARGOS; BARBOSA, 2005); diversificação de risco (TRICHES, 1996). De acordo com Wood Jr., Vasconcelos e Caldas (2004), as fusões e aquisições realizadas no mercado brasileiro apresentam interesses tipicamente estratégicos, visando a conquista de maior participação no mercado; ganhos operacionais; aumento na lucratividade; produtividade; ampliação da rede de distribuição e logística; e operações que almejavam à obtenção de know-how corporativo, de tecnologia, práticas gerenciais e de mercado.

Entretanto, estes e outros fatores microeconômicos adquirem relevância distinta dependendo do período econômico analisado, já que são fortemente influenciadas pelo ambiente macroeconômico em que estão inseridos (AUSTER; SIROWER, 2002). Neste sentido, este artigo estará focado nas principais mudanças macroeconômicas para explicar a evolução das transações de F\&A no país no período de 2002 a 2014.

\section{Mudanças Macroeconômicas}

As mudanças macroeconômicas efetuadas pelo governo brasileiro possuem um impacto direto sobre o ambiente de negócios empresariais, tendo o poder de alterar a atratividade da economia brasileira para investimentos e adequações da economia local à realidade das empresas internacionais (AMANN; BAER, 2008; MARION; VIEIRA, 2010). Além dos mecanismos adotados pelo governo brasileiro, se faz imprescindível considerar a influência do mercado internacional na construção deste cenário. Isso se justifica pelo fato do fluxo de capital estrangeiro contribuir com volumes significativos para a realização das transações no mercado local (KPMG, 2014). Adicionalmente, cada vez mais as economias dos diferentes países estão interligadas pelo efeito de contágio entre suas negociações internacionais e bolsas de valores (RIBEIRO et al., 2014). Desta forma, os impactos das alterações macroeconômicas nos movimentos de F\&A no Brasil foram analisados considerando-se duas visões: as interferências do governo brasileiro e as interferências do mercado externo.

\section{Interferências do Governo Brasileiro}

A abertura da economia brasileira tem como marco a última década do século 20. Neste período, o país iniciou um processo de alteração de estruturas de controle e promoção do comércio exterior. Desta forma, houve uma forte redução tanto de tarifas de importação como de barreiras não tarifárias. Como consequência, a taxa tarifária média de importação reduziu-se de 41\% em 1989 para 13,5\% em 2002, ampliando a competitividade no mercado local (AMANN; BAER, 2008). A abertura do mercado interno evidenciou uma diferença significativa de produtividade entre as empresas brasileiras e suas concorrentes estrangeiras, fruto do período anterior que contava com fortes intervenções estatais e restrições ao livre mercado (YANO; MONTEIRO, 2008). Desta forma, após a liberação comercial, houve uma alteração na estratégia das companhias, pois passaram a se preocupar de forma mais significativa à aquisição de capacidade tecnológica e eficiência produtiva (MARION; VIERA, 2010).

Concomitantemente, o presidente Fernando Collor iniciou em 1991 um processo de privatizações, restrito inicialmente aos setores de aço e petroquímico, que ganhou ímpeto em 1995, com a posse do Presidente Fernando Henrique Cardoso (FHC). Este último ampliou significativamente os setores com permissão de serem privatizados (PINHEIRO, 2000). Adicionalmente, o BNDES teve um papel decisivo neste processo, pois além de disponibilizar recursos, mesmo para empresas estrangeiras, o banco forneceu auxilio na condução de tais processos como gestor (CANO, 2002).

As reformas no sistema monetário realizadas por FHC com a implementação do Plano Real em 1994 (quando ainda era Ministro da Fazenda de Itamar Franco), e a introdução de um câmbio flutuante em 1999, promoveram respectivamente uma maior estabilização monetária, diminuindo sensivelmente o ritmo de elevação dos preços e da inflação, o que tornou a abertura comercial mais efetiva na reestruturação industrial e ampliou a atratividade de IED (CASTRO, 2001; BRITTO, 2002). Adicionalmente, em 1995, foram implementadas medidas que eliminavam a separação entre empresas nacionais e estrangeiras e uma nova lei de propriedade industrial ampliando a atratividade do capital estrangeiro ao país (MARION; VIEIRA, 2010).

A abertura da economia somada às privatizações e as reformas monetárias criou uma crescente onda de F\&A 
no Brasil. Para as companhias nacionais, a abertura representou um grande choque de competitividade, já que houve uma maior oferta de produtos importados no mercado local, reduzindo a demanda por produtos nacionais. Isso levou algumas empresas brasileiras, com desvantagem tecnológica e de capital - geradas pelo histórico de governos anteriores que preconizavam a substituição de importações -, a optar pela união com empresas estrangeiras e assim sobrepor os desafios decorrentes da globalização econômica (CANO, 2002; TRICHES, 1996).

Estes movimentos contribuíram para o aumento da concentração em muitos setores demandando que o governo brasileiro tomasse medidas para estabelecer uma legislação antitruste que preservasse e reprimisse infrações contra a ordem econômica (AMANN; BAER, 2008). Esta necessidade foi materializada na Lei 8884/94, que introduz orientações para F\&A e torna o Conselho Administrativo de Defesa Econômica (CADE) uma instituição independente. Apesar do crescente número de análises submetidas ao CADE, o grau de intervenção tem sido pequeno e decrescente, prevenindo de forma tímida a concentração setorial (AMANN; BAER, 2008).

Nesta última década as instituições brasileiras também promoveram alterações nas legislações relacionadas a qualidade da informação e ao padrão de divulgação contábil. No ano de 2000 foi promovida uma reforma legislativa focada na qualidade das informações do mercado de capitais com a implementação dos níveis diferenciados de governança (CARVALHO, 2002). Mais recentemente, com a aprovação da Lei 11.638/07 em 2008, revisou os aspectos contábeis das demonstrações financeiras brasileiras que passaram a apresentar uma maior convergência aos padrões internacionais consolidados no IFRS (Internacional Financial Reporting Standards). Estes movimentos evidenciam um esforço que o Brasil tem promovido para dar maior transparência ao seu mercado local e ampliar a atratividade de capital externo.

\section{Interferências do Mercado Externo}

Após um período de constante crescimento de investimentos estrangeiros no país, o Brasil viu seus ingressos externos caírem 69\% no período 2000-2003. Entre outros fatores, esta queda refletiu o aumento da percepção de risco tanto no mercado financeiro internacional, atrelado a crise das empresas ponto. $\underline{\text { com, }}$ como no local devido a eleição do Presidente Lula que gerou incertezas acerca da estabilidade econômica (UNCTAD, 2004). Adicionalmente, apresentou um fraco desempenho no PIB e o esgotamento das privatizações (UNCTAD, 2004). Os fluxos de IED tem relação direta com o nível de F\&A no país já que é considerado para seu cálculo qualquer aquisição de participação acima de $10 \%$ do capital de empresas domésticas por empresas estrangeiras (BCB, 2014).

A partir do ano de 2003, o crescimento do PIB foi recuperado e ampliado, com uma nova queda significativa somente em 2009, como consequência, entre outros fatores, da crise financeira mundial. Mesmo com a crise internacional e um baixo crescimento econômico nos anos mais recentes, no período em análise, com exceção de 2009, o IED cresceu consistentemente até 2011 quando atingiu seu recorde histórico com a inversão de US\$ 66,7 bilhões, conforme demonstrado no Gráfico 1 (BCB, 2014; UNCTAD, 2015). Em anos mais recentes, este volume apresenta certa estabilização que deve ser entendida em um contexto de forte crescimento nos anos anteriores.

Gráfico 1 - Investimento Estrangeiro Direto (IED) em US\$

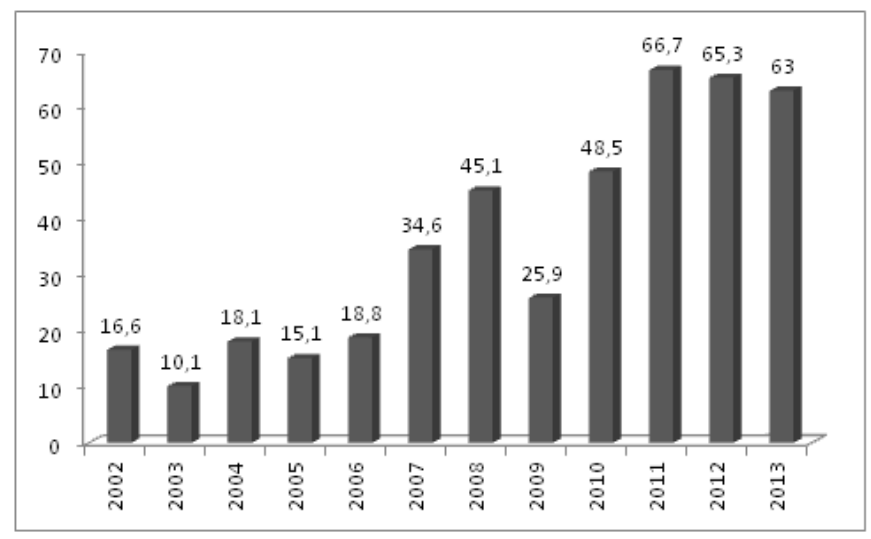

Fonte: Adaptado pelos autores a partir de BCB (2014) e UNCTAD (2015)

Este movimento pode estar diretamente relacionado à redução do risco país, fornecido pelas principais agências de rating, que é considerado um importante indicador para incentivos a investimentos, incluindo F\&A. Segundo Garcia e Didier (2003), "o risco país é um reflexo da situação econômica e financeira de um país, refletindo também a estabilidade política e o desempenho histórico no cumprimento de suas obrigações financeiras”. 
No período em estudo, o risco Brasil apresentou um recorde de alta em Setembro 2002 (2.436 pontos), devido à eleição do Presidente Lula e o temor do potencial calote da dívida externa, seguido de uma forte queda até 2008 (137 pontos), quando o risco Brasil foi elevado à categoria de grau de investimento (PORTAL BRASIL, 2014). Após uma leve tendência de alta, como consequência do choque externo da crise financeira mundial e o aumento da percepção de risco em todos os mercados, o índice voltou a apresentar reduções atingindo 259 pontos ao final de 2014 (PORTAL BRASIL, 2014).

Assim, pode-se inferir que os bons fundamentos das variáveis econômicas no período de 2002 a 2014 acabaram por reduzir o risco país. Este cenário econômico somado ao aumento dos níveis de transparência e leis antitruste com baixa rigidez proporcionaram um crescimento continuo do IED que, por sua vez, está diretamente relacionado aos movimentos de F\&A.

\section{Contexto Brasileiro no período de 2002 a 2014}

As fusões e aquisições no mercado brasileiro tem caráter tipicamente estratégico, dado que visam basicamente (i) a defesa da concorrência, através da ampliação da participação de mercado e obtenção de know-how corporativo e de tecnologia (ii) preservação de lucros, com ganhos operacionais e de produtividade e (iii) aumento do poder em relação ao mercado que atuam, ampliando as redes de distribuição e logística. (WOOD JR.; VASCONCELOS; CALDAS, 2004).

As operações de F\&As na economia brasileira apresentam uma tendência crescente ao longo da última década conforme detalhado no Gráfico 2. A sua evolução pode ser analisada em três patamares temporais distintos (ANBIMA, 2011; PWC, 2015; KPMG, 2014), nos quais o volume apresentado é significativamente superior a qualquer outro apresentado na série histórica: (i) no período de 2002 a 2005, as operações cresceram gradualmente atingindo 280 operações em média; (ii) no período de 2006 a 2009, ocorre um salto em 2007 que mesmo com a forte queda em 2009 mantém uma média de operações significativamente superior ao período anterior em 572 transações e (iii) no período de 2010 a 2014, novamente apresentando uma aceleração nas F\&A em relação ao patamar anterior, porém com certa estabilização nos anos recentes totalizando 795 transações em média.
Gráfico 2 - Volume de operações de F\&A no Brasil por Ano

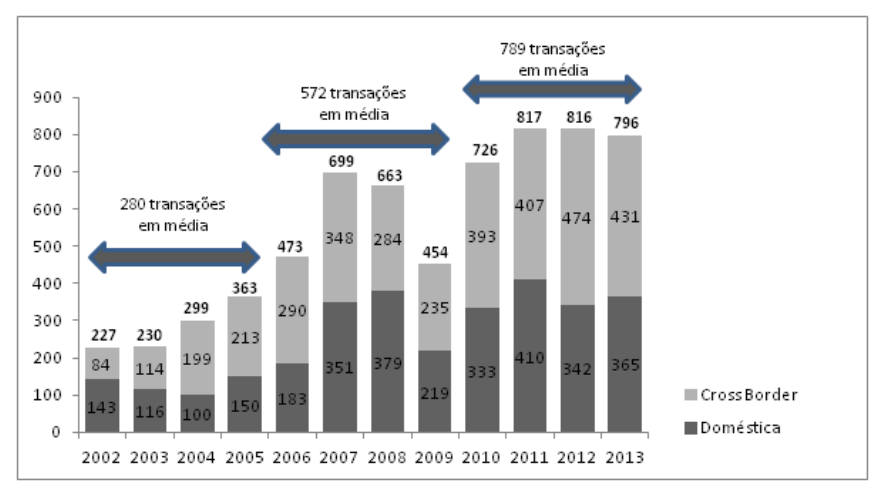

Fonte: Adaptado pelos autores a partir de KPMG (2014)

De acordo com a KPMG (2014), nestes treze anos ocorreram $7.381 \mathrm{~F} \& A$, dos quais $53,6 \%$ representaram transações envolvendo uma empresa brasileira e uma estrangeira (cross-border) e 46,4\% envolveram apenas firmas brasileiras (domésticas). A compreensão das operações cross border merece especial atenção para se explicar o desenvolvimento das F\&A no cenário brasileiro, uma vez que, com exceção dos anos 2002 e 2008, estas representaram o maior volume ou ficaram muito próximas aos níveis de transações domésticas nos anos analisados.

Vale salientar que as operações cross-border compreendem tanto transações que envolvem entrada como saída de capital do país. Uma análise mais detalhada desde dados é possível ser realizada apenas a partir de 2004, quando a KPMG passou a fornecer os dados das operações por origem de capital. Devido ao significativo fluxo de transações cross-border nos movimentos de F\&A e a diversidade de impactos que os incentivos do governo brasileiro geram nos diversos setores da economia, optou-se por ampliar a compreensão dos dados em análise considerando duas perspectivas: origem do capital e setor em que as empresas estão inseridas.

\section{F\&A por Origem do Capital (Cross-Border)}

Para enriquecer as análises, os países envolvidos nas operações cross-border foram agrupados em cinco blocos: África (AF), Ásia e Austrália (AA); Europa (EU); Estados Unidos e Canadá (EC); e Américas excluindo Estados Unidos e Canadá (AM). Estados Unidos e Canadá serão considerados isoladamente para as análises dado o alto volume histórico de operações destes dois países. 
Gráfico 3 - F\&A Cross Border por País

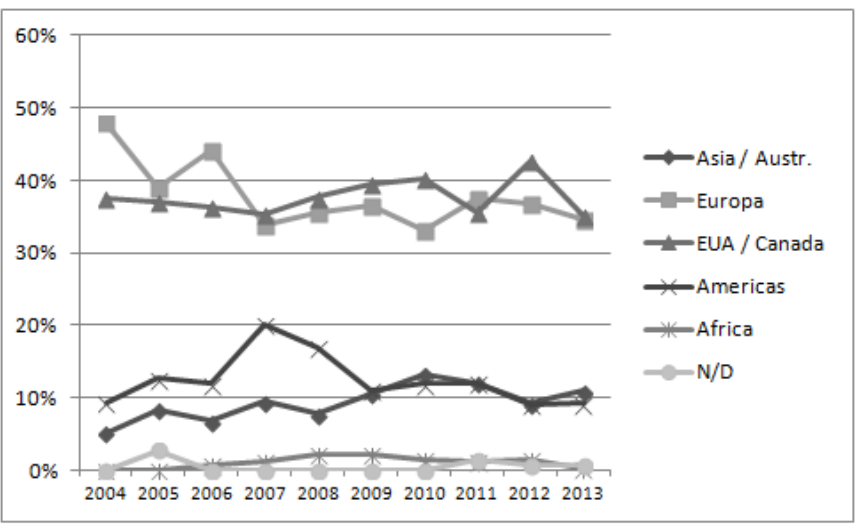

Fonte: Adaptado pelos autores a partir de KPMG (2004, 2005, 2006, 2007, 2008, 2009, 2010, 2011, 2012,2013,2014)

Conforme se pode observar no Gráfico 3, a participação do bloco EU apresentou uma redução temporária em 2005, principalmente por uma queda no volume de operações realizadas com a Espanha e Holanda (KPMG, 2005). Porém, retoma a liderança em 2006 atingindo 44\% do total de operações, com destaque para transações desenvolvidas com a França, Alemanha e Itália (KPMG, 2006). Entre 2007 e 2013, os EC se estabelecem na liderança em volume de operações, ficando momentaneamente atrás do bloco EU em 2011, devido ao aumento de operações com a França e o Reino Unido (KPMG, 2011). Em 2014, apesar de o bloco EC apresentar um aumento no número de transações, o EU retoma a liderança, principalmente, devido a um crescimento significativo das F\&A com o Reino Unido e Alemanha em 76,0\% e 32,0\% respectivamente (KPMG, 2014).

Em 2007, os países do continente AM apresentaram um pico de crescimento, com concentrações mais significativas com a Argentina, México e Chile (KPMG, 2007). Entretanto, este foi reduzido gradualmente ao longo dos anos. O bloco AA também ampliou sua participação no período, alcançando 13\% em 2010 e em 2014, impulsionado pelos negócios com a China e Cingapura (KPMG, 2010; KPMG, 2014). Em todo o período as transações realizadas com os países da $\mathrm{AF}$ apresentaram volume reduzido entre 1 a $2 \%$ do total. Mais detalhes acerca da participação dos diferentes blocos regionais no volume de fusões e aquisições serão disponibilizados na seção seguinte.

Os dados apresentados sugerem que, apesar de a crise internacional e de certa percepção de arrefecimento do entusiasmo global com o Brasil em anos mais recentes, o país se manteve na agenda de negócios de investidores estrangeiros. É relevante destacar que o volume de transações cross border envolvendo entrada de capital estrangeiro no país tem se ampliando gradualmente desde 2008, quando representavam $68 \%$ das operações. Este crescimento atingiu seu pico no ano de 2012, quando correspondeu a $86 \%$ das transações, apresentando uma redução nos últimos dois anos, atingindo 82\% em 2014.

\section{F\&A por Setor de Atividade}

Ao desenvolver uma análise das transações de operações de F\&A categorizadas por setor, os cinco setores que mais se destacaram em termos de volume foram os seguintes: Tecnologia da Informação (846 operações); Alimentos, Bebida e Fumo (567 operações); Companhias de Energia (387 operações); Serviços para Empresas (366 operações); e Telecomunicações e Mídia (330 operações).

\section{Gráfico 4 - Os Dez Setores mais Representativos em F\&A}

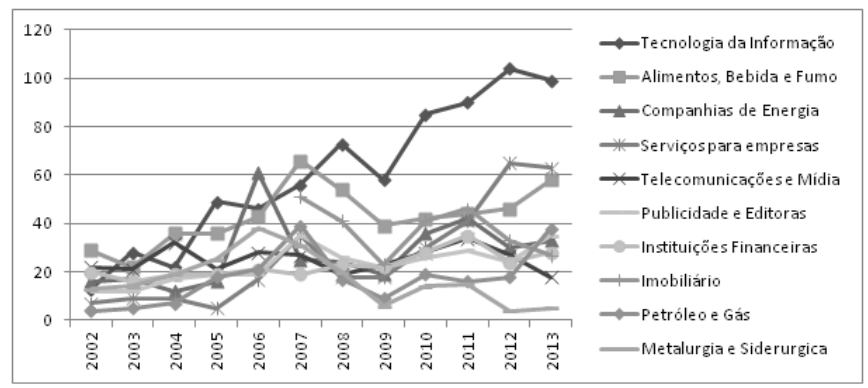

Fonte: Adaptado pela autora a partir de KPMG (2014)

Os setores de Tecnologia da Informação e Alimentos, Bebidas e Fumo mantiveram-se consistentemente entre os cinco primeiros setores em praticamente todo o período, conforme se pode observar no Gráfico 4. O setor de Tecnologia da Informação reportou expressivo aumento do volume de transações a partir do ano de 2004, mantendo uma tendência crescente até 2014. Já as operações no setor de Alimentos, Bebidas e Fumo cresceu gradualmente entre os anos 2003 e 2007, com uma inversão de tendência até 2009 , quando volta a apresentar um crescimento gradual. Adicionalmente, vale salientar alguns picos de crescimento de outros setores ao longo dos anos em análise: Companhias de Energia em 2006 e 2014; Imobiliário em 2007, quando é estabelecida uma categoria própria para este setor, com uma retomada em 2010 e 2011; e Serviços para Empresas em 2012 e 2013. 


\section{Análise dos dados}

\section{Relações entre a Origem do Capital e as Mudanças Macroeconômicas}

Como descrito anteriormente, a participação percentual das operações domésticas no volume de F\&A somente se sobressaíram em 2002 e 2008. Isso porque houve uma maior percepção de risco nos mercados externos devido à eleição do Presidente Lula e o agravamento da crise econômica mundial, respectivamente. Nos demais anos, as operações cross border tiveram maior representatividade. Vale destacar que dentre as operações de cross border a representatividade de operações com entrada de capital estrangeiro (Tipo 1) e saída de capital brasileiro (Tipo 2) oscilam ao longo do período, conforme a Tabela 1. A seguir, busca-se identificar quais fatores podem ter contribuído para este comportamento.

Tabela 1 - Origem do Capital das Operações Cross Border

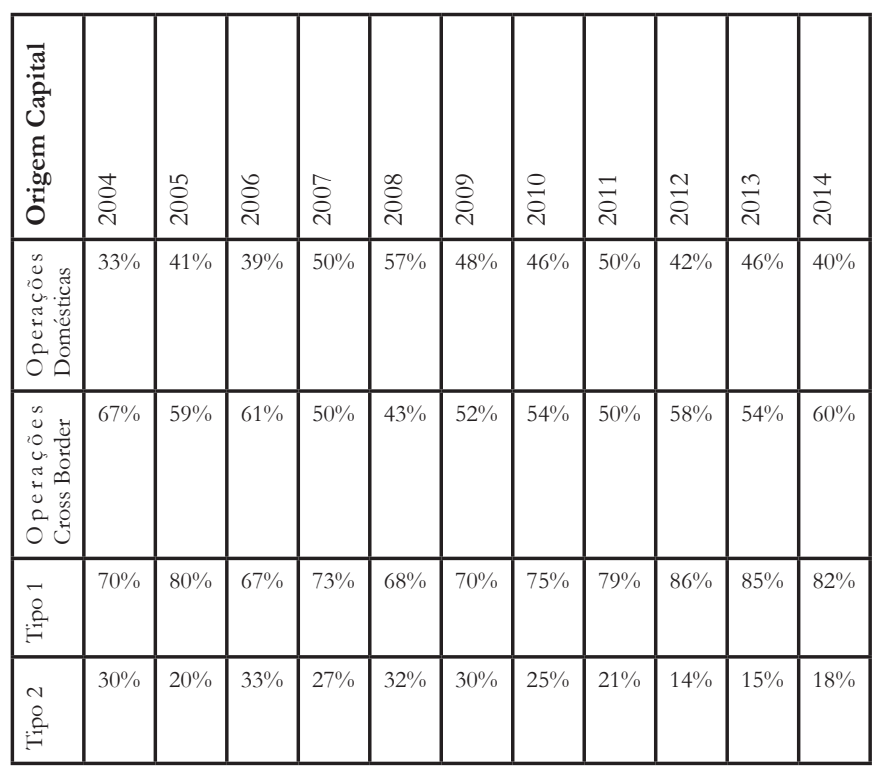

Fonte: Adaptado pelos autores a partir de KPMG (2014)

Com a eleição do Presidente Lula em 2002, e o potencial calote da dívida externa sob a perspectiva das agências de risco internacionais, criou-se um ambiente de incerteza que fez com que o risco país aumentasse consideravelmente (PAULANI, 2003), fato que retraiu as transações de F\&A cross-border. Com a acomodação das expectativas no ano de 2003 houve uma retomada do apetite dos investidores estrangeiros que, associado à abundância de crédito nacional e internacional, ampliou o fluxo de IDE e consequentemente o volume de F\&A cross-border a partir do ano de 2004 (UNCTAD, 2004).

Após uma participação decisiva nos processos de privatização ocorridos nos anos 1990, o BNDES voltou a ter um papel mais ativo na gestão do Presidente Lula. Uma mudança que merece destaque é o apoio deste banco a internacionalização de grupos econômicos nacionais a partir de 2005 , com o objetivo de tornálos capazes de concorrer internacionalmente (SOUZA, 2010; ROCHA, 2012). Este movimento é refletido no aumento das transações cross-border de empresas brasileiras adquirindo estrangeiras de 20\% em 2005 para 33\% em 2006 (KPMG, 2005; KPMG, 2006).

É interessante notar que apesar de haver uma redução do PIB em 2005 (3,2\%) e 2006 (4,0\%) em relação ao ano de 2004 (5,7\%), as transações de F\&A continuaram a apresentar uma tendência crescente. Além do apoio do BNDES, este movimento pode ser explicado pela natureza dos investimentos no período que está, em na sua grande maioria, destinada à compra ou participação em investimentos já existentes e não para a implantação e/ou ampliação de nova capacidade produtiva (LIMA JUNIOR, 2005).

Considerando o fluxo de operações cross border com entrada de recursos no país, o Bloco EU apresentou uma redução no volume de operações em 2005. Um destaque deve ser dado à redução dos negócios com a Espanha que potencialmente pode ser explicado devido à deterioração de seu cenário econômico interno. O aumento da inflação ampliou a aversão a risco diminuindo os investimentos para o desenvolvimento empresarial (SCANDIUCCI FILHO, 2005). Porém, o significativo crescimento de operações desenvolvidas com a França em 2006, relacionadas principalmente ao setor de varejo, com a concretização do acordo entre as redes Casino e Pão de Açúcar e a compra de ações da submarino.com (TERZIAN, 2007), levou o bloco EU novamente a liderança.

Os dados da UNCTAD (2007) sugerem que o bom momento econômico vivido pelo Brasil no ano de 2007 atraiu não só os investimentos estrangeiros tradicionais, de origem norte americana ou europeia, mas também de países latino americanos que viviam um momento de forte internacionalização. Este crescimento levou o Brasil de oitavo ao quarto maior receptor de investimentos entre os países emergentes em 2007 (UNCTAD, 2007). Estes fatores mantiveram as operações cross-border com crescimentos superiores 
as transações domésticas no período de 2004 a 2007.

A curva crescente de F\&A se viu fortemente impactada no último trimestre do ano de 2008, quando o Brasil foi afetado pela crise internacional. No entanto, a sensibilidade e o impacto foram menores que em outros países, fato que possibilitou que o volume de transações durante o ano de 2008, apesar de menor que em 2007, assemelhou-se ao de 2006, evidenciando um amadurecimento dos movimentos de F\&A no país (PWC, 2009b). A força do mercado interno tanto em operações domésticas como em cross border também foi decisiva para minimizar as consequências da crise mundial. As operações domésticas tiveram um crescimento de $8 \%$, principalmente fruto da consolidação de setores (PWC, 2008). Já as cross-border recuaram $18 \%$, porém as transações envolvendo empresas brasileiras adquirindo empresas estrangeiras domiciliadas ou não no Brasil cresceram cinco pontos percentuais em relação a 2007, representando 32\% das transações cross-border em 2008 (KPMG, 2007; KPMG, 2008).

Com o agravamento da crise internacional, ocorreu entre outros fatores, o aumento da incerteza nos mercados e a escassez de crédito, o que gerou uma retração nas operações de $\mathrm{F} \& A$. A redução dos investimentos não foi maior devido à intervenção do Estado através do BNDES, em sua segunda atuação decisiva no período. Além de suas funções tradicionais de fomento, o BNDES se tornou um instrumento da política fiscal anticíclica durante a crise, garantindo um expansionismo econômico (SOUZA, 2010; ROCHA, 2012). De forma genérica, uma maior atuação do Estado foi observada não só no Brasil, mas internacionalmente, tendo como foco apoiar as empresas a enfrentarem suas dificuldades financeiras (PWC, 2009).

No segundo semestre de 2009, há uma curva de recuperação da participação dos investidores estrangeiros retornando a patamares semelhantes aos da pré-crise, o que gerou a ampliação das operações cross-border em comparação às domésticas. Este movimento tem como fundamento a crescente atenção que os investidores externos têm despendido em países emergentes, entre os quais o Brasil se destaca no que tange à expansão de negócios e o retorno do investimento ao acionista (PWC, 2009b). O endereçamento de questões contábeis com a adoção do padrão IFRS, profissionalização de gestão e a busca por melhores níveis de governança corporativa também contribuíram para o desenvolvimento da atividade de F\&A (PWC, 2009).

Com a retomada ao final de 2009, o ano de 2010 iniciou fortemente aquecido, o que associado ao crescimento expressivo de IED nos últimos cinco anos, saindo de US \$ 15,1 bilhões em 2005 para US \$ 48,5 bilhões em 2010, viabilizou o alcance de patamares recordes de transações (UNCTAD, 2010). O Brasil se destacou como economia robusta e atrativa à medida que apresentou uma recuperação de forma mais acelerada que outras economias consideradas maduras, e reportou expectativa de crescimento quando o cenário mundial era de recessão (PWC, 2010). Adicionalmente, o Brasil foi o principal destino de investimentos chineses, tendo como perfil operações que viabilizavam acesso a recursos naturais (BBC BRASIL, 2011). Esta maior confiança do mercado brasileiro pode ser percebida não só no aumento expressivo de $67 \%$ nas operações cross-border, como também na ampliação da representatividade de transações envolvendo a entrada de capital estrangeiro no Brasil de 70\% em 2009 para 75\% em 2010.

Em um cenário de crise na Europa e lenta recuperação da economia americana em 2011, o Brasil bateu novo recorde no volume de IED, atingindo US\$ 66,6 bilhões, e de F\&A, o que confirmou uma menor sensibilidade às instabilidades e incertezas dos mercados internacionais. As operações domésticas foram as que apresentaram maior crescimento retornando a patamares acima dos níveis pré-crise no ano de 2008. Este fato sinaliza uma redução dos movimentos de internacionalização das empresas brasileiras que optaram pelo Brasil como sua principal plataforma de crescimento (KPMG, 2011).

Apesar de ter ocorrido uma redução da atividade econômica no Brasil no ano de 2012, o volume de F\&A foi praticamente mantido com recorde histórico de operações cross-border com entrada de capital estrangeiro ( $86 \%$ do total). Além da manutenção do cenário econômico apresentado no ano anterior (2011), um dos fatores que pode explicar o aumento do volume de F\&A é a reformulação dos métodos e critérios do CADE em Maio de 2012 (PWC, 2012). De acordo com a Portaria Ministerial 994/2012, o Conselho é obrigado a avaliar F\&A que envolvam empresas que faturem $\mathrm{R} \$ 750$ milhões por ano por um lado e $\mathrm{R} \$ 75$ milhões por outro, valor muito acima do texto original que previa mínimo de $\mathrm{R} \$ 400$ milhões e $\mathrm{R} \$ 30$ milhões respectivamente (CADE, 2012).

No primeiro semestre de 2013, observou-se uma redução das operações cross border. Este fato 
pode estar relacionado a expectativa de redução de crescimento do Brasil o que geraria uma ampliação do risco para este tipo de operação (KPMG, 2013). No entanto, no segundo semestre houve um crescimento de 7\% em relação ao mesmo período de 2012, indicando a retomada da atratividade principalmente para empresas que buscavam se estabelecer no país (KPMG, 2013).

Em 2014 observou-se uma retomada do crescimento de operações cross border, porém com uma elevação de transações com saída de capital brasileiro, ou seja, empresas brasileiras investindo no exterior para se internacionalizar. Esta busca pelo mercado internacional pode estar alinhada ao processo de recuperação econômica dos países desenvolvidos que teriam reduzido o risco de investimentos de longo prazo. Por outro lado, as transações domésticas reportaram o menor patamar dos últimos cinco anos, atingindo 331 operações. Um dos fatores que pode ter influenciado de forma decisiva a redução das operações domésticas foram as incertezas econômicas geradas pela eleição presidencial em Outubro, o que fez com que muitas companhias postergassem seus investimentos no aguardo do resultado das eleições (KPMG, 2014).

Portanto, em virtude da melhora dos indicadores macroeconômicos do país e sua nova capacidade de atração de investimentos, observou-se um crescimento nas F\&As, com taxa média anual de $11,3 \%$ no período compreendido entre os anos de 2002 e 2014, mesmo considerando as quedas apresentadas nos anos 2008, 2009 e 2013.

\section{Relações entre os Setores de Atividade e as Mudanças Macroeconômicas}

O setor de Tecnologia da Informação (TI) reportou desde o ano de 2004 um crescimento expressivo, tornando-se o setor mais relevante em termos de volume de F\&A a partir de 2008. A origem desta tendência pode estar fortemente relacionada à expansão significativa de investimentos do Governo Federal no setor de TI. Este movimento tinha por objetivo diminuir o "hiato digital" observado entre o Brasil e outros países, que teve como ferramenta a ampliação de escopo do porte das empresas elegíveis para a linha de financiamento PROSOFT, oferecida pelo BNDES (BATISTA et al., 2014). Esta linha de crédito possibilitou a expansão da participação de empresas nacionais no mercado interno, apoiando os seus investimentos em nova tecnologia e métodos, além de promover as exportações do setor (IBGE, 2009).

Um dos diferenciais deste setor é que sua curva de crescimento é ligeiramente independente do crescimento econômico do país, já que os serviços de tecnologia são demandados tanto em projetos de expansão e inovação como de redução de custos e ganhos de escala (BRASSCOM, 2011). Ademais, a participação de um número significativo de pequenas e médias empresas, e um fluxo contínuo de surgimento de pequenas empresas inovadoras, contribui para a ampliação da fragmentação do setor, que somadas às necessidades constantes de investimentos neste segmento mantém a atratividade dos movimentos de F\&A (BATISTA et al., 2014). Recentemente, a desoneração da folha de pagamento concedida pelo Plano Brasil Maior também pode ter impulsionado os investimentos e aquisições, gerando um crescimento vertiginoso em 2012 (BRASIL MAIOR, 2012).

O setor de Alimentos, Bebidas e Fumo é um dos mais tradicionais no Brasil e tem seu volume de operações beneficiado pela expansão da demanda interna, estabilização da economia, forte atividade de aquisição entre empresas nacionais como estratégia de expansão e pelo alto potencial de crescimento em relação a mercados mais desenvolvidos (RODRIGUES, 1999). Este setor apresenta um pico de crescimento no ano de 2007 sustentado pela consolidação das empresas brasileiras no mercado local já que muitas delas abriram capital nos dois anos anteriores e partiram para uma política agressiva de aquisições a fim de crescer rapidamente e gerar resultados para os acionistas (KPMG, 2007).

Outro setor que merece destaque no período é o que envolve operações das Companhias Energéticas. Este setor reportou nos últimos vinte anos um ápice de operações em 2006, e uma retomada do crescimento de transações em 2014, com 61 e 56 operações respectivamente. Em 2006, as operações foram impulsionadas pelas necessidades de geração de eletricidade do país, detalhadas no Plano de Expansão de Energia do Governo Federal entre 2006-2015, e a promulgação da Lei Federal 10.848/04 que proibiu empresas de distribuição exercer atividades de geração e transmissão de energia. Esta mudança na legislação gerou uma desverticalização do setor e impulsionou o movimento de F\&A, já que as empresas buscaram consolidarem rapidamente suas posições, pois, de outra forma, ficariam estagnadas em um mercado 
interno maduro (PEREIRA, 2007).

Já no ano de 2014, o setor viu suas receitas serem reduzidas com a aprovação da Lei 12.783/2013, que ademais de renovar as concessões estabelece uma revisão tarifária. Este fato desencadeou um movimento de consolidação, principalmente entre as companhias nacionais, responsáveis por $52 \%$ das operações, na busca por redução de custos e sinergias operacionais (KPMG, 2014).

Nos anos de 2012 e 2013, o setor de Serviços para Empresas bateu seu recorde de negócios em um único ano ficando em segundo lugar no ranking por segmento da KPMG. Vale ressaltar que $92 \%$ de todas as operações neste setor foram originadas por companhias estrangeiras, fato que pode ser compreendido pelo potencial do mercado consumidor e forte pulverização de mercado (KPMG, 2012). Apesar de o setor de Telecomunicações não apresentar picos significativos, reporta um volume consistente impulsionado em anos mais recentes pelas transações envolvendo as companhias "pontocom" (KPMG, 2011).

\section{Considerações finais}

Este artigo teve por objetivo contribuir para a reflexão sobre a evolução das transações de F\&A no país no período de 2002 a 2014. Após uma análise dos principais fatores envolvendo estes tipos de operações, pode-se observar que mesmo com um cenário econômico em constantes alterações positivas e negativas, o volume de F\&A no Brasil apresentou uma tendência ascendente ao longo do período em análise. Este comportamento foi sustentado principalmente por operações cross border, que corresponderam a $53,6 \%$ de todas as transações no período em estudo. Os dados dos anos mais recentes proporcionam indicativos de que este tipo de transação continuará ampliando sua representatividade e assim poderá manter os patamares de volume de F\&A observados.

Este resultado corrobora com as observações de Medina (2005) que aponta quea atratividade do mercado brasileiro e sua relevância se mantém constantes devido à abertura comercial, desregulamentação dos fluxos financeiros, estabilidade econômica e oportunidades relativas ao tamanho do mercado doméstico. Adicionalmente, Souza (2010) observa que no médio prazo as multinacionais brasileiras têm como estratégia expansões através de F\&A em novos países o que pode garantir a manutenção de patamares elevados de operações cross border.

Assim, entre os principais fatores que impulsionaram o volume de F\&A desempenhados pelo governo brasileiro destacam-se: (i) a maior estabilidade econômica e política interna verificada pela redução da volatilidade do risco país; (ii) a atuação do BNDES tanto no fomento de internacionalizações em 2005 como na ampliação de crédito nos anos de 2008/2009; (iii) a expansão e atratividade de mercado interno apresentando altas taxas de retorno; e (iv) baixa legislação antitruste o que facilita os processos de F\&A. Cano (2002) destaca que a baixa atuação de órgãos antitruste contribui de forma decisiva para os movimentos de fusões e aquisições e pode ser considerado um mecanismo do governo que objetiva reestruturar o mercado local e atrair capital estrangeiro.

Já os fatores externos que parecem ter impactado de forma significativa o volume de F\&A foram: (a) o cenário de crise econômica internacional nos anos de 2008/2009; e (b) percepções de agências de rating e governos de países desenvolvidos acerca do cenário brasileiro tanto de forma negativa relacionada a instabilidades econômicas, como a eleição do Presidente Lula em 2002 e possível desaceleração da economia em 2013; como de forma positiva, por considerar um mercado que apresenta oportunidades de investimento com altas taxas de retorno em um cenário de desaceleração e/ou baixa recuperação mundial.

Adicionalmente, pode-se observar que o crescimento do volume de F\&A no período em estudo não representa uma evolução circunstancial. Mesmo com períodos com menor expectativa de crescimento no país, o mercado de F\&A se manteve aquecido confirmando que este tipo de operação ainda é uma das estratégias mais utilizadas para a expansão de empresas como já observado por Wood Jr. et al. (2004) e Amann \& Baer (2008). Se analisado atentamente, o volume de operações pode ser classificado em três patamares temporais distintos. Cada patamar apresenta um volume médio significativamente superior a qualquer outro apresentado na série histórica. Este fato sugere que houve um amadurecimento do mercado brasileiro ao longo dos treze anos investigados.

O setor de Tecnologia da Informação destaca-se no período de análise se mantendo na liderança do volume de operações a partir de 2008. Este crescimento acentuado está relacionado não só a consolidação do setor conta com diversas pequenas e médias empresas, mas também aos incentivos promovidos pelo BNDES 
e o baixo valor de mercado das transações quando comparado com companhias americanas e europeias (BATISTA et al., 2014).

Por fim, diante das observações acima expostas se nota que o estudo de F\&A no Brasil ainda apresenta lacunas para pesquisas futuras. Dentre estas, estaria um estudo mais apurado da contribuição do Estado (brasileiro ou estrangeiro) nos investimentos em F\&A, principalmente em situações de crise. Tais análises poderão somar ainda mais para o desenvolvimento de uma compreensão mais apurada das atividades de F\&A no Brasil. Vale salientar que este trabalho apresenta como limitação o detalhamento das informações disponibilizadas e classificadas pela KPMG, podendo apresentar distorções com relação a outros bancos de dados.

\section{Referências}

AMANN, E.; BAER,W. Neo-liberalism and market concentration in Brazil: The emergence of a contradiction?. The Quarterly Review of Economics and Finance, v. 48, p. 252-262, 2008.

ANBIMA - Associação Brasileira das Entidades dos Mercados Financeiro e de Capitais. Informativo ANBIMA - Especial Fusões e Aquisições, 2011. Disponível em: http://www.anbima.com.br/mostra. aspx/?id=4275. Acesso em: 19 nov. 2013.

ANTONIOU, A.; ARBOUR, P.; ZHAO, H. Measuring the economic gains of mergers and acquisitions: is it time for a change?, 2006. Disponível em: http://papers.ssrn.com/sol3/papers. cfm?abstract $\mathrm{id}=579841$. Acesso em: 27 mai. 2015.

AUSTER, E.R.; SIROWER, M.L. The dynamics of merger and acquisition waves: a three-stage conceptual framework. The Journal of Applied Behavioral Science, v. 38, n. 2, p. 216-244, jun. de 2002.

BATISTA, C. N.; PESSANHA, G. R. G.; GONÇALVES, L.R.; NOGUEIRA, L. R. T.; CANDIDO, M. S. Impacto das fusões e aquisições na rentabilidade das empresas adquirentes: uma análise do setor de tecnologia da informação brasileiro no período de 1994 a 2013.

Artigo apresentado no XVII SEMEAD, São Paulo, out. 2014.

BBC Brasil - British Broadcasting Corporation. Brasil foi o principal destino de investimento chinês em 2010, 2011. Disponível em: http://www. bbc.co.uk/portuguese/noticias/2011/04/110410 invest china br ss.shtml. Acesso em: 19 nov. 2013. BCB - Banco Central do Brasil. Investimento Estrangeiro Direto, 2014. Disponível em: http:// www.bcb.gov.br/pre/portalCidadao/cambio/ investEstrang.asp?idpai=PORTALBCB. Acesso em: 18 jun. 2014.

BHAGAT, S.; MALHOTRA, S.; ZHU, P. Emerging country cross-border acquisitions: characteristics, acquirer returns and cross-sectional determinants. Emerging Markets Review, v. 12, p. 250-271, 2011.

BRASSCOM - Associação Brasileira das Empresas de Tecnologia da Informação e Comunicação. Sem retração, serviços de Tecnologia avançam no país e alavancam o PIB, 2011. Disponível em: http://www. brasscom.org.br/brasscom/Portugues/detNoticia. hp? codNoticia $=53 \& \operatorname{cod}$ Area $=2 \& \operatorname{codCategoria}=26$. Acesso em: 21 nov. 2013.

BRASIL MAIOR. Inovar para competir. Competir para crescer, 2012. Disponível em: http://www.brasilmaior.mdic.gov.br/images/ data/201211/2f197bbf4dfd7e05c57703fd75673ec2. pdf. Acesso em: 21 nov. 2013.

BRITTO, G. Abertura comercial e reestruturação industrial no Brasil: um estudo dos coeficientes do comércio. Dissertação de Mestrado em Economia. Universidade Estadual de Campinas. Campinas, 2002.

CADE - Conselho Administrativo de Defesa Econômica. Resolução no. 2, de 29 de Maio de 2012, 2012. Disponível em: http://www.cade. gov.br/upload/Resolu\%C3\%A7\%C3\%A3o\%20 2 2012\%20-\%20An\%C3\%A1lise \%20Atos\%20 Concentra\%C3\%A7\%C3\%A3o.pdf. Acesso em: 13 nov 2013.

CANO, M. O recente processo de fusões e aquisições na economia brasileira. Dissertação de Mestrado. Universidade Estadual de Campinas. Campinas, 2002.

CAMARGOS, M. A. de; BARBOSA, F. V. Fusões, aquisições e takeovers: um levantamento teórico dos Motivos, hipóteses testáveis e evidências empíricas. Caderno de Pesquisas em Administração, v. 10, n. 2, p. 17-38, 2003.

CAMARgOS, M. A. de; BARBOSA, F. V. Análise do desempenho econômico- financeiro e da criação de sinergias em processos de Fusão e Aquisição do 
mercado brasileiro ocorridos entre 1995 e 1999.

Caderno de Pesquisas em Administração, São

Paulo, v. 12, n. 2, p. 99-115, abr./jun. 2005.

CARVALHO, A. G. Governança Corporativa no Brasil em perspectiva. Revista de Administração, São Paulo, v. 37, n. 3, p. 19-32, 2002.

CASTRO, A. B. A reestruturação industrial brasileira nos anos 90. Um interpretação. Revista de

Economia Política, São Paulo, v. 21, n. 3, jul./set. 2001.

DODD, P. Merger proposals, management discretion and stockholder wealth. Journal of Financial

Economics, v. 8, n. 2, p. 105-137, 1980.

\section{EL HAJJ, Z. S. Business combination e}

consolidação: uma abordagem comparativa entre as normas do US-GAAP, IASC e Brasil. Dissertação de Mestrado em contabilidade. Faculdade de Economia, Administração e Contabilidade, Universidade de São Paulo. São Paulo, 1999.

GARCIA, M. G. P.; DIDIER, T. Taxa de juros, risco cambial e risco Brasil. Pesquisa e Planejamento Econômico, Rio de Janeiro, v. 33, n. 2, p. 253-297, ago. 2003.

IBGE - Instituto Brasileiro de Geografia e Estatística. O setor de Tecnologia da Informação e Comunicação no Brasil 2003-2006, 2009.

Disponível em: http:/ www.ibge.gov.br/home/ estatistica/economia/stic/publicacao.pdf. Acesso em: 21 nov. 2013.

KPMG - Klynveld Peat Marwick Goerdeler. Pesquisa de Fusões e Aquisições - 40 .

Trimestre. 2004 - 2014 (por ano). Disponível em: http://www.kpmg.com/BR/PT/Estudos Analises/

RSSFeeds/Paginas/Corporate-Finance.aspx. Acesso em: 01 abr. 2014.

LIMA JUNIOR, A. J. M. Determinantes do investimento direto estrangeiro no Brasil.

Dissertação de Mestrado. Faculdade de Ciências Econômicas, Universidade Federal de Minas Gerais (UFMG). Belo Horizonte, 2005.

LOPES, C. C. V. M. Combinações de empresas pelo método de compra dos ativos: análise comparativa entre as normas do IASB e as do Brasil. Revista Contabilidade e Finanças - USP, São Paulo, Edição Comemorativa, p. 79-87, 2003.

MARION, P. J.; VIEIRA, G. Fusões e aquisições (F\&A) de empresas no Brasil (1990-2006). Revista
Administração (UFSM). Santa Maria, v. 3, n. 1, p. 109-130, jan./abr. 2010.

MEDINA, A. J. Determinantes do investimento direto estrangeiro no Brasil. Dissertação de Mestrado. Faculdade de Ciências Econômicas, Universidade Federal de Minas Gerais (UFMG). Belo Horizonte, 2005.

PAULANI, L. M. Brasil Delivery: a política econômica do governo Lula. Revista de Economia Política, v. 23, n. 4, out./dez. 2003.

PEREIRA, M. A. S. Fusões e Aquisições. Um estudo em uma empresa nacional do Setor Elétrico. Dissertação de Mestrado. Administração, Faculdade Novos Horizontes. Belo Horizonte, 2007.

PINHEIRO, A.C. A experiência brasileira de privatização: o que vem a seguir?. BNDES. Rio de Janeiro, 2000.

PORTAL BRASIL. Cotação diária do dólar, euro e do "Risco Brasil". 2002-2014, 2014. Disponível em: http://www.portalbrasil.net/2013/economia/ cotacoes dolar real riscopais.htm, Acesso em: 20 mai. 2015.

PWC - Pricewaterhouse Coopers. Fusões e Aquisições no Brasil, Dezembro. 2008-2014 (por ano). Disponível em: http://www.pwc.com.br/pt/ publicacoes/servicos/fusoes-aquisicoes.jhtml. Acesso em: 30 mai. 2015.

Integração pré e pós Fusões e Aquisições no Brasil 2008- 2009, 2009b. Disponível em: http:// www.pwc.com.br/pt/estudos-pesquisas/assets/resppesq-ceo-08.pdf. Acesso em: 12 Nov. 2013.

RIBEIRO, F.; BARBOSA, J. S.; FONSECA, M. W.; FREGA, J. R. Impacto da crise financeira de 2008: um estudo sobre as variações do coeficiente beta no mercado de capitais brasileiro. Revista Capital Científico - Eletrônica, v. 12, n. 1, jan./mar. 2014. Disponível em: http://200.201.10.18/index.php/ capitalcientifico/article/view/2528/98. Acesso em: 01 abr. 2014.

\section{RODRIGUES, R.I. Empresas Estrangeiras}

e Fusões e Aquisições: os casos dos ramos de autopeças e de alimentação/bebidas em meados dos anos 90. Brasília: Instituto de Pesquisa Econômica Aplicada, jan. 1999.

ROSS, S. A.; WESTERFIELD, R. W.; JAFFE, J. F. Administração Financeira: Corporate finance. São Paulo: Atlas, 2002. 
ROCHA, D. O. Estado Empresariado e Variedades de Capitalismo no Brasil:

Internacionalização de Empresas Privadas no Governo Lula. Dissertação de Mestrado. Universidade de São Paulo Instituto de Relações Internacionais. 2012.

SCANDIUCCI FILHO, J. G. Desequilíbrios Externos da Economia Espanhola. Revista Economia Política Internacional: Análise Estratégica (UNICAMP), n. 7, out./dez. 2005.

SOUZA, A. M. O expansionismo nos governos Lula e o BNDES. Meridiano 47, v. 11, n. 120, p. 47-53, 2010.

SPOHR, N.; SILVEIRA, F.F.; Estratégia internacional de uma multinacional emergente brasileira: o caso JBS. Revista de Administração Estratégica (RAE), v. 52, n. 3, p. 300-312, jun. 2012.

STRAUB, T. Reasons for frequent failure in mergers and acquisitions: a comprehensive analysis. Editora Springer DE, 2007. Deutscher Universitätsverlag, Wiesbaden, 2007.

SUEN, A.S.; KIMURA, H. Fusões e Aquisições como estratégia de entrada (Entre Mode) no Mercado Brasileiro. Caderno de Pesquisa em Administração, v. 2, n. 5, p. 53-60, 2 semestre de 1997.

TANURE, B.; CANÇADO, V. L. Fusões e Aquisições: aprendendo com a experiência brasileira. RAE-Revista de Administração de Empresas, v. 45, n. 2, p. 0-22, abr./jun. 2005.

TERZIAN, F. Gigantes vão as compras. Revista França Brasil, n. 284, set./out. 2007. Disponível em: http://www.conteudoeditora.com.br/ publicacoes $/$ ?ec $=284 \& c s=16$. Acesso em: 23 jan. 2014

TRICHES, D. Fusões, Aquisições e outras formas de associação entre firmas no Brasil. Revista de Administração, São Paulo, v. 31, n. 1, p. 14-31, jan./ mar. 1996.

UNCTAD - Conferência das Nações Unidas sobre comércio e desenvolvimento. World Investment Report 2004: the shift towards services: New York e Geneva, 2004. Disponível em: http://www.unctad. org/en/docs/wir2004 en.pdf. Acesso em: 28 out. 2013.
.World Investment Report 2007:

Transnational corporations, extractive industries and development. New York e Geneva, 2007. Disponível em: http://unctad.org/en/docs/wir2007 en.pdf.

Acesso em: 23 nov. 2013.

.World Investment Report 2010: Investing in a low-carbon economy. New York e Geneva, 2010. Disponível em: http://unctad.org/en/docs/wir2010 en.pdf. Acesso em: 23 nov. 2013.

.Global FDI flows declined in 2014: China becomes the world's top FDI recipient. New York e Geneva, 2015. Disponível em: http://unctad.org/ en/PublicationsLibrary/webdiaeia2015d1 en.pdf.

Acesso em: 18 mai. 2015.

WOOD JR., T.; VASCONCELOS, F. C.; CALDAS, M. P. Fusões e Aquisições no Brasil. RAE

Executivo, São Paulo, v. 2, n. 4, p. 41-45, jan. 2004. YANO, N.M.; MONTEIRO, M. M. Mudanças institucionais de 1990 e seus efeitos sobre a produtividade total dos fatores. In: ENCONTRO NACIONAL DE ECONOMIA, 36, 2008. Disponível em: http://www.anpec.org. br/encontro2008/artigos/200807211610100-.pdf. Acesso em: 21 mai 2015. 